\title{
CONSTRUÇÃO POLÍTICA DA DISPONIBILIDADE HÍDRICA: O CASO DO SERTÃO SEMIÁRIDO
}

Rita Alcântara Domingues*

Resumo: Este trabalho objetiva construir uma análise crítica acerca dos efeitos das ações de organizações do governo federal, como a Chesf e a Codevasf, a partir das mudanças institucionais que caracterizaram o quadro geral do planejamento regional associado ao uso dos recursos hídricos no semiárido brasileiro. No arcabouço teórico, destaca o pensamento de Douglass North (1993) sobre a Nova Economia Institucional, que resgata conceitos como de instituições e organizações. Pauta-se no reconhecimento de que as ações dessas organizações, seguindo diretrizes institucionais, fazem parte do processo de construção do território. Conclui que as mudanças institucionais e as ações de tais organizações são responsáveis por uma estruturação territorial no submédio São Francisco - sertão semiárido nordestino.

Palavras-chave: Região Nordeste; Submédio São Francisco; Organização Territorial.

\section{CONSTRUCTION OF WATER AVAILABILITY POLICY: THE CASE OF SERTÃO}

\begin{abstract}
This paper aims to build a critical analysis of the effects from the actions of the federal government organizations, such as Chesf and Codevasf, as of institutional changes that characterized the general framework of regional planning associated with the use of water resources in semiarid Brazil. The theoretical framework highlights the thought of Douglass North (1993) on the New Institutional Economics, which rescues concepts such as institutions and organizations. Guided by the recognition that the actions of these organizations, following institutional guidelines, are part of the construction of the territory. It concludes that the institutional changes and the actions of such organizations are responsible for structuring a territorial sub medium São Francisco - semi-arid northeastern sertão.
\end{abstract}

Key Words: Northeast Region; Sub medium San Francisco; Territorial Organization.

\section{Introdução}

Em regiões de relativa escassez hídrica, como o semiárido nordestino e o submédio São Francisco, (Croqui 1) a existência de um manancial do porte e extensão do rio São Francisco extrapola os limites de um acidente geográfico e de um bem público isolado, para se converter numa matriz de possibilidades estratégicas, da qual depende toda a população.

O território do submédio São Francisco, situado na divisa dos estados de Pernambuco e Bahia - sertão nordestino -, assume funções além do espaço local, atingindo a dimensão regional, quando o uso das águas é disputado pela Companhia Hidrelétrica do São Francisco (CHESF), para geração de energia elétrica, pela Companhia de Desenvolvimento do Vale do São Francisco $(\text { CODEVASP })^{1}$, para irrigação, e, no momento, pela instância do governo federal, com a trans-

\footnotetext{
${ }^{1}$ Essa companhia substituiu a CVSF e a SUVALE.
}

* Universidade Federal Rural de Pernambuco (UFRPE). E-mail: rima7@hotlink.com.br. 
posição de águas do rio São Francisco².

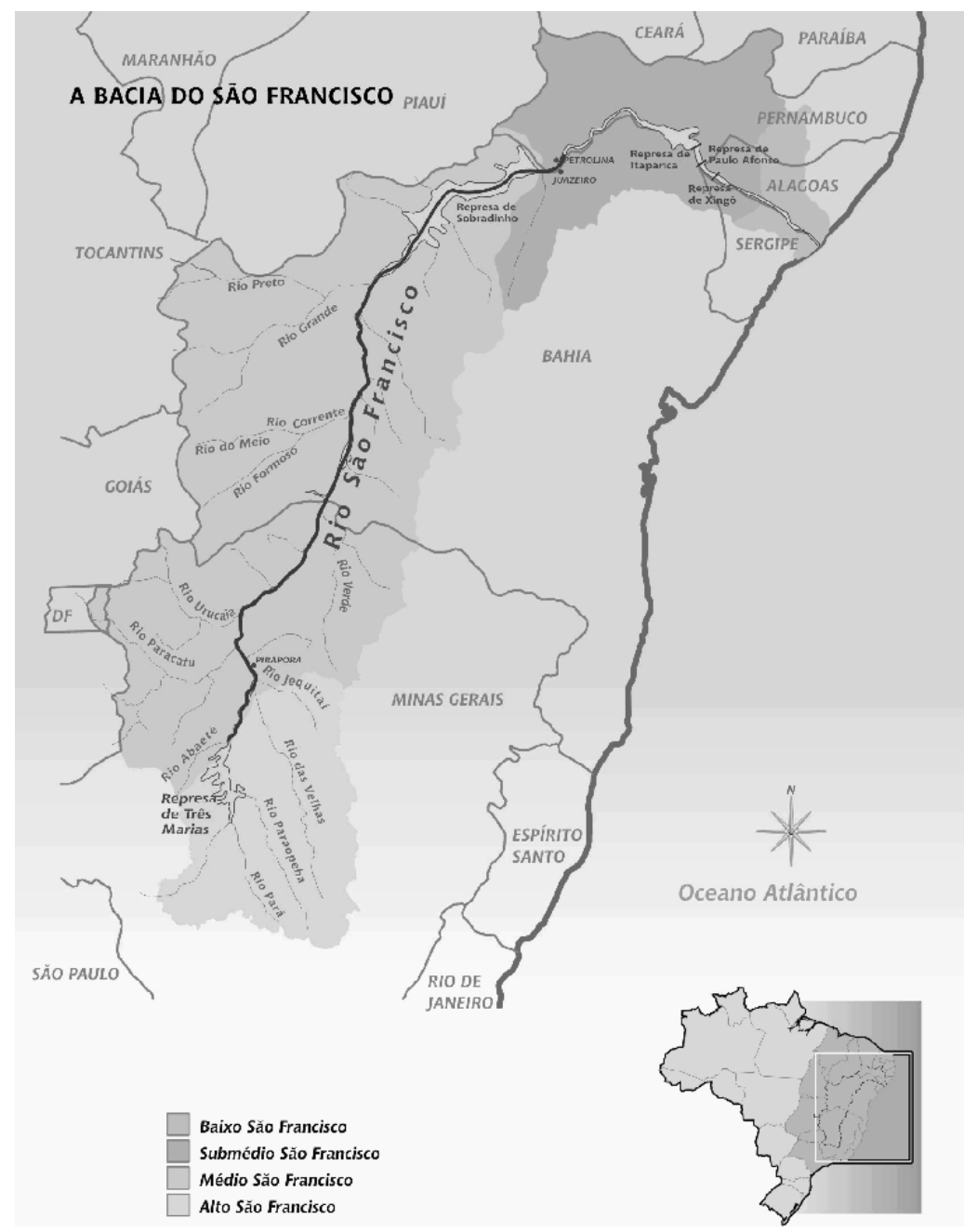

Croqui 1: Bacia do rio São Francisco e regiões hidrográficas.

Fonte: BRASIL. Ministério da Integração Nacional. Novos limites, 2004.

O foco que norteia este trabalho é: em que medida a escassez ou disponibilidade de água e a definição de seus usos pelo quadro institucional são consideradas responsáveis pela organização e estruturação do submédio São Francisco?

Constituindo parte das reflexões da tese de doutorado intitulada Aspectos institucionais da gestão dos recursos hídricos: o caso do submédio São Francisco (DOMINGUES, 2006), este estudo adota uma perspectiva de análise das mudanças institucionais e das ações das duas organizações mencionadas, como agentes estruturadores e de transformação do território, por meio da adoção de políticas públicas capazes de definir usos e a base material do território. Para tanto, algumas questões metodológicas e instrumentos teóricos respaldam a análise. Tem destaque, nessa reflexão, o arcabouço teórico desenvolvido pelo economista Douglass North (1990, 1992), a respeito da Nova Economia Institucional, que resgata os conceitos de instituições e organizações.

\footnotetext{
2 O projeto de transposição de parte das águas do rio São Francisco vem sendo apresentado como alternativa para reduzir a oferta desigual de água na região sertaneja (EIA/RIMA, 2004, p. 25). Sua primeira etapa prevê a construção de gigantescas tubulações e canais num percurso de $1440 \mathrm{~km}$ de extensão, cujo objetivo, segundo o governo, é dar segurança hídrica a uma população de 12 milhões de pessoas e irrigar o sertão dos estados do Ceará, Rio Grande do Norte (Eixo Norte $-402 \mathrm{~km}$, transportando $45,2 \mathrm{~m}^{3} / \mathrm{s}$ ) e Pernambuco e Paraíba (Eixo Leste - $220 \mathrm{~km}$ ), seguindo até o rio Paraíba, na Paraíba, transportando, em média, $18,3 \mathrm{~m}^{3} / \mathrm{s}$ de água.
} 
O trabalho está inserido numa análise crítica sobre o método histórico e dialético, e parte da premissa de que tanto a realidade quanto as instituições, além de não serem estáticas, são contraditórias e dialéticas.

\section{A emergência de um padrão}

\section{institucional no submédio São Francisco}

\section{É possível observar um padrão} institucional no submédio São Francisco, no que tange à utilização dos recursos hídricos. Dois usos refletem, de modo claro, esse padrão: a energia elétrica e a irrigação. A cada um corresponde uma organização com lógica de atuação diferenciada, embora haja interdependência entre elas, uma vez que não se pode compreender o território, encarando os elementos isoladamente, fora dos fenômenos circundantes (STALIN apud LAKATOS e MARCONI, 2000, p.84).

Metodologicamente, no primeiro momento, serão abordadas as ações da Companhia Hidrelétrica do São Francisco (CHESF), que, ao longo dos anos, constituiuse numa organização dominante para o setor elétrico na região. Como companhia de eletricidade, tornou-se centro de decisão e controle dos recursos hídricos, assumindo posição hegemônica durante algumas décadas. No segundo momento, o trabalho concentrar-se-á nas ações da Companhia de Desenvolvimento do Vale do São Francisco (CODEVASF), no âmbito da irrigação, setor apontado como principal usuário consuntivo. Vale lembrar que, na prática, essa divisão estrita não é possível, porque as ações dessas organizações apesar de individualizadas, elas se misturam e se complementam, ou seja, caminham paralelamente, tocando-se em vários momentos.
Entre 1909 e 1945, a preocupação do governo federal com o Nordeste estava ligada, basicamente, à acumulação de água com vistas às soluções hidráulicas ${ }^{3}$. Depois, as mudanças na economia impuseram novos usos para as águas do rio São Francisco (CHESF, 1998, p.151; LEITE 1997, p.95).

Para atingir tal objetivo, a Chesf, ligada à presidência da República, era dotada de flexibilidade na gestão de seus recursos e na adoção de soluções técnicas. Tratava-se, de fato, de gerar energia para uma região que não havia sido bem atendida pelas empresas do grupo Amforp ${ }^{4}$ ou por empresas locais. A Chesf obteve concessão pelo prazo de cinquenta anos, para efetuar o aproveitamento progressivo de energia elétrica do rio São Francisco, no trecho compreendido entre Juazeiro (BA) e Piranhas $(A L)^{5}$.

A criação da Chesf representou o marco inaugural de um novo estágio no desenvolvimento do setor elétrico, com o envolvimento direto do Estado nesse campo. Contudo, atrás dessa ação havia um sentido mais abrangente, uma vez que a preocupação do governo com a seca deixou de ser apenas no campo assistencialista, e voltou-se para a adoção de planejamento para a região. Nessa situação, é possível estabelecer diálogo com as ideias de Veblen (Velho institucionalismo), que reconhece a existência de uma relação entre a instituição e a necessidade que a fez surgir, a qual resulta, quase sempre, numa defasagem das instituições.

\footnotetext{
${ }^{3}$ Naquele momento, apontava-se como problema do Nordeste a falta de água, e a solução viria da engenharia, com a construção de açudes.

${ }^{4}$ American and Foreign Power Company (Amforp), organizada em 1923 pela Electric Bond and Share e atuante no Brasil a partir de 1927.

5 A área de atuação da empresa foi inicialmente definida por um raio de $450 \mathrm{~km}$ em torno de Paulo Afonso. Vale salientar que $90 \%$ dessa área estavam localizados na demarcação do Polígono das Secas. Em agosto de 1964, o decreto n.o 54.160 ampliou a área de concessão da Chesf de $450 \mathrm{~km}$ para $700 \mathrm{~km}$, em torno da cachoeira de Paulo Afonso (CHESF, 1998, p.37).
} 
Com o fortalecimento do setor elétrico, implantou-se um dos pilares do desenvolvimento nacional, não só com o abastecimento de energia elétrica das cidades, mas também com o acionamento do equipamento fabril, condição essencial para o ingresso do Nordeste brasileiro no estágio da industrialização, já disseminada no Centro-Sul do país desde os anos 1930. Nessa concepção, a energia elétrica desempenhava papel fundamental, como alavanca do processo de desenvolvimento, o que, em muitos momentos, confundia a companhia de energia elétrica com a companhia de desenvolvimento.

Ao tratar de alternativas ou estratégias de desenvolvimento regional, a economia dá a possibilidade de análise, via equações e abstrações da própria ciência. No entanto, segundo autores da Velha Economia Institucional, como Veblen (1965), também, é possível integrar a economia a outras ciências sociais, numa abordagem multidisciplinar. É nesse sentido que este estudo segue.

Dando continuidade a essa política de ampliação da infraestrutura de geração de energia elétrica para fins econômicos, o governo Dutra instituiu a primeira equipe para a construção de represa e a implantação de uma usina de grande capacidade, para fornecer energia aos principais centros urbanos da área. Paralelamente, entrou em funcionamento o primeiro circuito de alimentação da rede de Recife, por meio de linhas de transmissão. A potência gerada foi de $180.000 \mathrm{~kW}$, que representava mais do que o dobro da capacidade disponível na região. Para se ter ideia do que isso significava, a capacidade total de geração na região era, na época da inauguração, de 110.000kW (CHESF, 1998). Havia, também, a necessidade de utilização da energia para o desenvolvimento agrícola, para viabilizar a irrigação. Assim, naquele momento, tal modelo tinha como base uma política industrial e agrícola, e o uso das águas para geração de energia era visto sob uma perspectiva diferente, com a possibilidade de frear o acelerado processo de desequilíbrio entre as duas regiões: Nordeste e Sudeste brasileiros.

Na nova visão, o governo reconheceu a necessidade de aproveitar as águas acumuladas durante a fase das soluções hidráulicas $^{6}$, bem como a utilização dos recursos hídricos para outros usos $^{7}$, como condição direta do desenvolvimento econômico. Paralelamente à criação da empresa específica do setor elétrico, e inspirada na Tennessee Valley Authority (TVA), após a II Guerra Mundial, nasceria, em 15 de dezembro de 1948, a Comissão do Vale do São Francisco (CVSF) ${ }^{8}$, concebida para desencadear o Plano de Aproveitamento do Vale do São Francisco, que preconizava a importância do uso das águas do rio São Francisco para navegação (1952), irrigação (1950) e geração de energia elétrica.

A extensa gama de responsabilidades atribuídas à CVSF promoveu uma série importante de ações, que resultaram na construção da barragem hidrelétrica de Três Marias $^{9} \mathrm{em}$ convênio com as Centrais Elétricas de Minas Gerais (CEMIG), com funções múltiplas de regularização do rio, e viabilizou, posteriormente, a construção da barragem hidrelétrica de Sobradinho (médio curso), além da implantação de projetos pioneiros de irrigação no médio e submédio São Francisco,

\footnotetext{
${ }^{6}$ Por "soluções hidráulicas", entende-se o momento em que o modelo de desenvolvimento para o Nordeste viria por meio do armazenamento de água e, nesse caso, são típicos os agentes institucionais, Inspetoria Federal de Obras Contra as Secas (IFOCS), a princípio, e o Departamento Nacional de Obras Contra as Secas (DNOCS), posteriormente, responsáveis pela ação instrumental.

7 Os termos "usos múltiplos" e "bacia hidrográfica como unidade de planejamento" foram oficializados mais adiante, com a Lei n. ${ }^{0}$ 9.433/97.

8 O seu primeiro Plano Quinquenal foi para o período de 1951-55.

Foi construída de 1957 a 1962, ano de sua inauguração.
} 
principalmente em Petrolina e Juazeiro. Vêse, portanto, que foram ações conjugadas em dois sentidos: o primeiro, na geração de energia elétrica, e o segundo, na implantação de irrigação.

Para melhor compreensão do que esse arranjo institucional representou décadas depois, a irrigação, sobretudo a privada, passou a comandar o processo de produção agrícola no polo Petrolina-Juazeiro e, de modo geral, tem sido extremamente eficaz no processo de modernização e criação de empregos, constituindo-se, também, num instrumento de crescimento socioeconômico do semiárido nordestino. Para Domingues (1989, p.213), os projetos de irrigação podem ser considerados como a "mola mestra" do crescimento econômico do polo.

Ainda com relação ao quadro regional, num momento de significativa importância do papel da Chesf e da CVSF, o sertão brasileiro vivenciou grande seca, no período de 1951-53, ocasião que levou o governo a introduzir mudanças, como a criação de outro agente, o Banco do Nordeste, destinado a financiar a infraestrutura da região. Porém, o ano de 1958, em que ocorreu outra grande seca, serviu para constatar que a solução pautada na açudagem, ainda que combinada com ações de agências como o IFOCS (malha rodoviária), a CVSF e a Chesf (energia elétrica farta), não era capaz de resolver o problema da estagnação da região.

Naquele contexto, foi criado o Grupo de Trabalho para o Desenvolvimento do Nordeste (GTDN), que, seguindo orientação de Celso Furtado, aprofundou as análises em busca dos problemas reais e de soluções que pudessem ser viabilizadas mediante uma nova organização, a Superintendência de Desenvolvimento do Nordeste (SUDENE), no final dos anos 1950.
Nesse sentido, é possível ir além da mera tentativa de compreensão, não se conformando com uma imagem simplificada e redutora do quadro regional. Para Veblen (1965), na origem da abordagem institucional, as regras não se materializavam, necessariamente, em ordens executadas, pois, hierarquizadas, misturavam-se, combinavam-se e se reforçavam ou se contradiziam, possibilitando a sobrevivência das instituições, ainda que em desequilíbrio. A Sudene seria, pois, uma forma de assegurar a liderança do governo federal no processo de desenvolvimento e uso de receitas por meio do planejamento regional.

Para Francisco de Oliveira (1981, p.37-38), o diagnóstico do quadro regional que antecedeu a criação dessa agência incorporava elementos do falso conflito interregional, para ganhar força e dar maior dimensão à própria definição da região Nordeste. Suas respostas vieram, no sentido reformista, em 1959, com a criação da Sudene, por meio da Lei n.0 3.692, de 15 de dezembro de 1959, que identificava o problema central do Nordeste como de caráter econômico, e não mais natural, observando que a estratégia do planejamento regional, naquele momento, era a industrialização.

Sendo a Sudene órgão de planejamento regional, sem dúvida, ela trabalhava conjuntamente com a Chesf e a CVSF, posto que as estratégias de desenvolvimento estavam calcadas tanto na industrialização como na implantação de sistemas agrícolas modernos, uma vez que não eram, naquele momento, muitas as alternativas para a região. A partir de 1964, a atuação do governo seguiu duas direções: recriar condições para a retomada da expansão da economia e fornecer as bases institucionais adequadas à instauração da eficácia do mercado como elemento ordenador da economia. 
Com relação à região Nordeste, o aumento acelerado da demanda de eletricidade determinou a construção do maior conjunto energético do país e o primeiro a ultrapassar a marca de $1.000 \mathrm{MW}$ (CHESF, 1998).

No que se refere à política de irrigação, no final da década de 1960, foi estruturado pelo governo federal o Programa Plurianual de Irrigação (PPI), visando à implementação de estudos, projetos e obras de irrigação e drenagem, particularmente na região semiárida do país. Sua base era 0 aproveitamento dos pequenos e grandes açudes existentes, de cursos d'água perenes e água subterrânea. Em setembro de 1966, a CVSF $^{10}$ deixou de dispor de recursos constitucionais para o Vale, situação essa reiterada pela Constituição de 1967. À comissão pioneira sucedeu a Superintendência do Vale do São Francisco (SUVALE), em fevereiro de 1967, por recomendação de estudos conjuntos da CVSF, da Sudene, e da Chesf. Dentre as principais conclusões desse estudo, foi demonstrada a existência de três milhões de hectares de terras potencialmente irrigáveis no Vale, além de um potencial de 12.500MW de energia hidrelétrica (BRASIL, 2003).

Segundo relatório do Senado Federal (BRASIL, 1995), em 1972, o governo federal criou o Programa Especial para o Vale (PROVALE), visando a complementar programas existentes e, novamente, a partir de estudos da Development and Resources

\footnotetext{
${ }^{10}$ A Comissão do Vale do São Francisco foi, durante os vinte anos de sua existência, a grande provedora de infraestrutura do vale do São Francisco, por meio de conjunto de dados básicos, levantamentos e estudos de aproveitamento setorial, planos regionais e estaduais de desenvolvimento integrado e outros, que permitiram identificar e quantificar as potencialidades do vale, principalmente, no que se refere à irrigação e navegação.
}

Corporation, dirigida pelo fundador da TVA ${ }^{11}$ foi proposta a reformulação da Suvale e criada a Companhia de Desenvolvimento do Vale do São Francisco, em 1974. Somente no final dos anos 1970, foi divulgado o primeiro texto legal sobre a irrigação no Brasil, com a edição da Lei n. ${ }^{\circ} 6.662$ - a Lei de Irrigação -, de 25 de junho de 1979. Sua regulamentação ocorreu em 29 de março de 1984, por meio do decreto n.o 89.496, quando então se instrumentalizou no plano legal a irrigação. Observa-se, portanto, o arranjo institucional criado.

Reiterando a forma de abordagem aqui proposta, encontra-se na Teoria das Instituições e da Mudança Institucional de North (1993) um novo programa de investigação, que se apoia, cada vez mais, em argumentos institucionais, para explicar os complexos problemas do crescimento econômico em perspectiva histórica.

O programa de irrigação teve por finalidade o desenvolvimento socioeconômico da região e pretendia contribuir para o equacionamento de um amplo conjunto de problemas e deficiências estruturais do setor. Tais ações seriam implantadas pela Codevasf, estabelecendo uma relação entre as ações governamentais e a iniciativa privada, com ênfase, porém, no capital privado. Esse modelo era compatível com a política nacional, e, como resultado das ações, favoreceu grupos locais fortes, empresas externas à área. Ainda, mantendo-se a tendência de concentração do capital, a produção era voltada, sobretudo, para a exportação, em vez de beneficiar a população local.

11 O modelo americano (TVA), dos anos 1930, estabelecia um programa para conservação e melhoria do uso da terra e dos recursos hídricos, em toda a bacia hidrográfica do Tennessee, com proposta de coordenação dos diferentes usos. No Brasil, esse modelo foi o maior inspirador do projeto da Codevasf, e consistia em destinar $1 \%$ do orçamento da União para recuperar o vale do rio São Francisco. 
Por outro lado, em termos de mercado de trabalho - apenas com relação ao polo PetrolinaJuazeiro -, a importância da agricultura irrigada fica mais clara, quando se confronta o número de empregos por ela criados com o total rural da região (DOMINGUES, 1989, p.208).

Acrescentando-se às estratégias nacionais de desenvolvimento a industrialização como alternativa da economia, a energia devia ser consolidada e adequada ao processo de desenvolvimento regional. Por meio da Sudene, deveria ser incentivada a transferência de parte do capital industrial do Sudeste para o Nordeste, deslocando, para essa região, atividades que certamente liderariam o crescimento industrial, possibilitando o dinamismo na área.

Assim, a legislação federal (ambiente institucional) aprovou o Primeiro Plano Diretor da Sudene (Lei n.0 3.995, de 14 de dezembro de 1961), e instituiu um mecanismo de dedução do imposto de renda para as empresas de capital nacional que aplicassem essa dedução em investimentos industriais no Nordeste do país. Dois anos mais tarde, os benefícios desses incentivos foram estendidos às empresas transnacionais e aos empreendimentos agropecuários. Os recursos seriam oriundos do Fundo de Investimento do Nordeste (FINOR) e dos mecanismos de incentivos fiscais, conhecidos como Artigo 34 da Lei n.0 3.995 de 14 de dezembro de 1961 e Artigo 18 da Lei n.o 4.239 de 27 de junho de 1963, que na prática serviram, de fato, ao financiamento da expansão de grandes empresas.

No submédio São Francisco, vários projetos industriais foram aprovados e, paralelamente, os projetos públicos de irrigação, que permitiram às indústrias de beneficiamento agrícola ampliar a escala de produção e, ao mesmo tempo, constituir um mercado de peso de maquinaria e insumos agrícolas.

Com base nessa política de incentivos, houve, sem dúvida, avanço representado pela ruptura com a política de açudagem, embora, mais uma vez, "não se questione a existência da grande propriedade, nem tampouco a fragilidade da classe trabalhadora e as relações de produção perversas" (GOMES, 1995, p.74). Com tal postura, as ações do governo assumiram os contornos da ideologia da classe dominante da região.

O comportamento apontado é compatível com as ideias de Veblen (1965, p.178-179), da Velha Economia Institucional, uma vez que vincula instituições a tipos de caráter, a indivíduos, normalmente, da classe dominante, que, uma vez selecionados, moldarão as instituições a sua imagem e semelhança.

Dessa forma, o fortalecimento da economia nordestina seria promovido por setores cujos responsáveis eram os empresários e, por outro lado, a eliminação do problema aconteceria no lado mais frágil, dos trabalhadores, que, historicamente, ficaram à margem de qualquer grande projeto que tenha sido pensado como solução. Para Andrade (1983, p.23), não se deve confundir "os interesses e as aspirações do Nordeste com os interesses e as aspirações da classe dominante, que se beneficia do subdesenvolvimento". Nesse caso, as organizações que definiram o padrão institucional na região estavam influenciadas pelo jogo de poder entre as oligarquias dominantes dos nordestes (canavieiro-têxtil e algodoeiro-pecuário) e, ainda, do Centro-Sul, marcando presença em todas as etapas do processo: implantação, atuação e definição de políticas públicas de uso do espaço.

Nos anos 1980, o setor elétrico brasileiro caracterizava-se pela hegemonia de empresas estatais, pela baixa 
competitividade e falta de estímulo à eficiência e à competição, fatores que culminaram com tarifas defasadas, obras paralisadas e inadimplência setorial generalizada (ANEEL, 1999, p.113). Entretanto, Oliveira (2001, p.150), trabalhando a perspectiva da Chesf, admite que seu declínio teve início já no princípio dos anos 1960, quando a empresa começou a sofrer os efeitos da perda de autonomia, em virtude da criação do Ministério de Minas e Energia (MME), ao qual passou a subordinarse, deslocando-se da ligação direta que mantinha com o gabinete da Presidência da República.

A década de 1990 tornou-se um marco, e, como resultado dessa política, verifica-se disparidade entre oferta e demanda elétrica. Ainda nesse período, o Estado abandonou sua trajetória histórica de responsabilizar-se por investir em setores estratégicos, presumindo poder transferir, logo em seguida, a responsabilidade dos investimentos para empresas privadas, e proclamou que passaria a priorizar 0 saneamento de suas contas. Nessa conjuntura de reestruturação, ele assumiu a postura de privatizar as empresas estatais, sob a alegação da necessidade de melhorar a eficiência dos serviços prestados à comunidade, abater as dívidas e, ao mesmo tempo, inserir-se com competitividade no cenário mundial.

A privatização do setor elétrico não é um processo uniforme. Existem grupos que podem constituir, com relativa facilidade, atividades independentes, enquanto em outros, considerados usinas chave de sistema e respectivos troncos de interligação regional, a situação torna-se mais complexa, pois a possível privatização seria em conjunto com as correspondentes usinas chave (LEITE, 1997, p.321-328). Nesse cenário, foi prevista a privatização da Chesf.
É bom lembrar que as empresas públicas de energia surgiram em um momento histórico, em que o Brasil estava na fase de substituição das importações, precisando de indústrias e serviços que melhorassem sua infraestrutura. O setor público, naquele momento, surgiu como proposição pragmática, voltada para a promoção do desenvolvimento e, por trás desse processo, estava o Estado. Aqui, podese fazer uma comparação do processo de criação de estatais ocorrido no passado e o processo de privatização que ocorre no presente. O primeiro foi determinado no espaço político nacional, enquanto o segundo é elitizado e impulsionado por forças exógenas, embora pactuadas com as elites locais.

Então, de que modo essa política repercutiu nas ações da Codevasf? Houve redução na expansão das áreas com irrigação, inclusive, comprometendo parcialmente a implantação dos reassentados da barragem Itaparica, apesar da participação dos recursos do Banco Mundial, posto que não havia a contrapartida financeira do governo brasileiro. Contudo, além da bacia do rio São Francisco, a Codevasf teve sua área acrescida, incorporando, sob sua responsabilidade, a irrigação da bacia do Parnaíba/PI.

Assim, aquela década foi portadora de dois processos de extrema relevância para a evolução do setor elétrico e, consequentemente, para o desenvolvimento industrial e econômico do país. O primeiro estava ligado às mudanças estruturais ocorridas no setor, que iam desde a privatização da geração, distribuição e algumas linhas de transmissão de alta tensão, até a criação das agências reguladoras: Agência Nacional de Energia Elétrica (ANEEL), em 1996, Agência Nacional de Águas (ANA), em esfera federal e 
estadual, e um Operador Nacional do Sistema Elétrico (ONS). O segundo processo foi a deflagração de uma crise no setor elétrico brasileiro, que ocasionou diversos impactos ao país, nos âmbitos econômico, político e social.

Mais recentemente, no final dos anos 1990, o país promoveu uma nova alteração na estrutura institucional, desencadeada por mudanças macroeconômicas e conjugada com uma nova visão sobre a importância da água como um bem finito. Essa concepção deveu-se à preocupação mundial no que se refere ao déficit de água que afligirá a Terra neste milênio. Aquela mudança refletiu-se na Lei $n .^{\circ}$ 9.433, de 8 de janeiro de 1997, que adotou um novo arranjo institucional para a "gestão dos recursos hídricos".

O novo arranjo institucional propôs a descentralização no poder de decisão, abrindo espaço para organizações não governamentais. Foi criado o Sistema Nacional de Gerenciamento de Recursos Hídricos, que integra conselhos, comitês e agências, como o Conselho Nacional de Recursos Hídricos (CNRH), a Agência Nacional de Águas (ANA) e agências de água, e inclui a participação de atores da sociedade civil no processo decisório.

No setor energético, o ano de 2001 revelou o fim do mito de que o país tinha energia abundante para sustentar o crescimento econômico. O contexto de crise exigia mudanças radicais para adaptação a um novo modelo setorial que compatibilizasse a privatização, o livre acesso à rede de transmissão por qualquer agente do sistema e as novas formas de comercialização.

No que se refere à irrigação, Guivant (1998) indica a necessidade de articular vários níveis institucionais, no sentido de promover um novo modelo de agricultura nacional. O autor ressalta a importância do papel do Estado como indutor de política setorial, das instituições de pesquisa e de outras instituições e organizações de apoio, dentre os fatores estruturais fundamentais para o desenvolvimento da agricultura sustentável. Isso de alguma forma justificase, no Brasil, na ação estratégica do Estado, quando mantém sob sua tutela o principal sistema de pesquisas agropecuárias do país a Empresa Brasileira de Pesquisas agropecuárias (EMBRAPA) -, em abrangência nacional, e a implantação de projetos de irrigação - Codevasf -, no âmbito da área específica.

Assim, é possível perceber que o padrão institucional e o desempenho econômico caminham juntos, e podem ser um recurso para entender o peso e a importância das ações de organizações em determinada região, especificamente, no submédio São Francisco. Portanto, essa percepção ocorre ao se concentrar a atenção na adoção de estratégias, normas e procedimentos que conferem força política e econômica a determinadas organizações. Inclui-se, nesse caso, a Chesf, empresa que define, na região, o uso para geração de energia elétrica, e a Codevasf, companhia que, indiretamente, estrutura o espaço produtivo com modernas técnicas agrícolas de irrigação, como responsáveis pela organização territorial no submédio São Francisco-sertão semiárido nordestino.

\section{Reflexão Teórica: visões institucionalistas}

Este item volta-se para as bases conceituais da abordagem institucional, cujas origens estão associadas aos trabalhos de Veblen (1965), para, em seguida, apresentar as contribuições mais recentes, vinculadas, principalmente, às concepções de Douglass North (1993). Esta reflexão contempla, ainda, a perspectiva institucional na geografia econômica. 


\section{O velho institucionalismo}

Nos últimos anos, observa-se o interesse na importância das instituições para a análise econômica, embora não exista um acordo quanto à forma de tratamento, nem quanto às implicações de incorporá-las. Os institucionalistas americanos foram os primeiros a destacar a importância econômica dos hábitos de conduta e de pensamento dos grupos humanos e a analisar e compreender o complexo papel das instituições sociais na dinâmica econômica.

A perspectiva institucional de Veblen (1965) tem sua origem na corrente de pensamento americana de economia política, dominante entre 1890 e 1940 . Essa corrente, que foi influenciada pela escola histórica alemã do século XIX (Hildebrand, Knies e Schmoller), utilizava conceitos procedentes da psicologia e do evolucionismo darwinista britânico e criticava a exclusão das instituições do núcleo da economia. Para Dutraive (1995), essa perspectiva de análise era verdadeiramente original, ao ocupar um espaço entre o vazio institucional de abordagem neoclássica e o todo institucional da abordagem durkheiminiana.

A fundamentação do trabalho de Veblen está na própria concepção de instituição como conjunto de ideias, modos de pensar compartilhados, hábitos sociais passíveis de ser identificados e mutáveis no tempo e no espaço. Assim, a instituição não teria a materialidade de uma entidade, isto é, definia-se pela maneira própria dos indivíduos de conceber a organização da vida comum, incluindo-se aí o direito de propriedade, conjunto de regras e contratos sociais.

Pode-se dizer, pois, que o velho institucionalismo adota uma concepção cultural de formação e evolução dos valores e do comportamento social. Destaca, ainda, o papel dinâmico do progresso técnico, suas contradições com as instituições estabelecidas e as estruturas sociais, como aspecto central de sua teoria de mudança social. Apresenta uma visão histórica e evolutiva do processo de transformação econômica e social, e adota, como ponto de partida da análise, a sociedade com seus comportamentos. Atribui grande importância ao poder e ressalta o papel do Estado, destacando os sistemas ideológicos e de poder expressos nas esferas política e governamental, como variáveis que determinam a evolução do processo de desenvolvimento. Há um diálogo entre o quadro regional nordestino em questão e o entendimento institucionalista de Veblen, conforme discutido no item anterior.

Apesar dos avanços teóricos, o dilema da economia institucional deve-se ao fato de ser difícil representar suas conclusões mediante um conjunto de equações, devido à complexidade e subjetividade dos problemas. Nesse caso, suas teorias são informais, ainda que alguns tenham feito grandes esforços para formalizar suas ideias e construir seus modelos.

\section{Nova Economia Institucional}

Na década de 1990, um conjunto de conceitos e métodos de análises econômicas, que esteve em elaboração por quarenta anos, encaixou-se como peças em um quebracabeça, para compor o que foi chamado de Nova Economia Institucional. Entre os maiores destaques teóricos dessa escola, podem ser citados Douglass C. North, Ronald H. Coase, Gary Becker e James M. Buchanan. Para Martínez Coll (2001, p.4), a corrente mais destacada e concorrida da Nova Economia Institucional é a conhecida Law and Economics, ou seja, Economia do Direito, que 
analisa os custos de transação e os direitos de propriedade. Os nomes mais fortes dela são Coase, Alchian, Demsetz Posner e Williamson. Outra fecunda corrente é a Economia Política Constitucional, definida pelos trabalhos de Buchanan, e que supera a mais ortodoxa Public Choice. Neste artigo, apenas alguns autores, dentre eles North, Coase e Williamson, serão explorados com detalhes.

A nova economia institucional considera o indivíduo como ponto de partida da mudança, mas se diferencia ao dar grande importância às instituições, inclusive destacando como fundamentais as normas formais e informais, regras, leis e hábitos de conduta. É, portanto, uma ampliação de seus postulados, que levariam a entender melhor o comportamento dos agentes econômicos e políticos.

Para Martin e Sunley (2000, p.3941), alguns economistas explicavam 0 diferencial de crescimento econômico, em longo prazo, entre países ricos e pobres, por meio de fatores exógenos, enquanto outros entendiam que tal crescimento se devia a fatores endógenos ${ }^{12}$. North tornou-se um dos precursores a relacionar instituições ao desempenho econômico das nações ${ }^{13}$. O marco analítico capaz de aumentar a

\footnotetext{
${ }^{12}$ As evidências empíricas da convergência regional no mundo industrializado revelam que sua taxa é muito mais lenta do que a proposta pelos modelos ortodoxos neoclássicos, persistindo a necessidade de uma abordagem teórica alternativa. A teoria do crescimento endógeno oferece algum avanço, à medida que os fatores chave por ela sustentados retornos crescentes de capital humano e tecnologia - desenvolvem-se desigualmente na economia espacial, sendo local e regionalmente diferenciados. Ela também pressupõe que os conceitos de doméstico e de endógeno não são sinônimos (MARTIN; SUNLEY, 2000, p. 39-41).

13 North procurou responder a duas questões: a primeira diz respeito aos motivos que levam países a ter trajetórias de crescimento tão divergentes; a segunda refere-se à insistência de caminhos desastrosos de crescimento em alguns países. 0 autor vinculou a resposta a essas duas questões ao binômio crescimento econômico e instituições de cada país (apud PASSANEZI, 2002, p. 16-17).
}

compreensão da evolução histórica das economias incorpora a instituição e a dimensão temporal na investigação.

North (1993) começou a esboçar um novo programa de investigação, que se apoiaria, cada vez mais, em argumentos institucionais, para explicar os complexos problemas do crescimento econômico em perspectiva histórica.

Outros autores, como Williamson (1993), adicionaram pontos importantes a essa corrente de pensamento, todavia, segundo alguns estudiosos, foi de Coase a contribuição mais relevante, com a teoria dos custos de transação. Para essa teoria, os custos de transação tendem a aumentar, quando as instituições são consideradas frágeis. Na busca por uma substituição da racionalidade dos modelos explicativos, Williamson (1993) avança teoricamente e mostra que, num contexto em que o mercado é insuficiente, a instituição impõe-se na função de coordenação. North (1993) vai mais além, e coloca que essa teoria pode ser um instrumento pertinente, tanto para a história econômica quanto para a análise da dinâmica institucional, no processo de crescimento e desenvolvimento econômico.

Esse último autor (1993, p.7) define instituições como um conjunto de regras, procedimentos de aceitação e normas de comportamento morais e éticos, criados para restringir o comportamento dos indivíduos. As instituições políticas e econômicas formam a estrutura de incentivos de uma sociedade e, portanto, são determinantes fundamentais do desempenho econômico. O tempo, segunda categoria de análise, tanto se relaciona com as mudanças econômicas e sociais como constitui uma dimensão na qual - processo de aprendizagem (terceira categoria) ocorre, favorecendo, assim, o desenvolvimento das instituições. 
Ampliando o conceito de instituição econômica, North (1993) aponta a existência de normas implícitas ou explícitas, que regulam a adoção de decisões dos agentes e limitam, voluntária ou involuntariamente, sua capacidade de decidir. Isso é o que ele chama de regras formais (regras políticas, de caráter jurídico, leis e constituições) ${ }^{14}$ e informais (convenções, normas de comportamento, hábitos de conduta, regras não escritas, porém aceitas) ${ }^{15}$. Dentre elas, existe interdependência e complementaridade, posto que as instituições informais influenciam as instituições formais. Em sua dinâmica e movimento, elas constituem um processo imaterial que se materializa no espaço.

North estende sua análise às organizações, que, assim como as instituições, proveem estrutura para a interação humana, mas com elas não se confundem. Segundo o autor,

[...] as organizações se compõem de grupos de indivíduos unidos por um propósito comum. As organizações são políticas (partidos políticos, congressos, agências reguladoras), econômicas (empresas, sindicatos, cooperativas), sociais (igrejas, clubes, associações) e educativas (escolas, universidades) (NORTH, 1993, p.7-8).

Partindo dessa concepção, o North

distingue instituições e organizações: as primeiras como as regras do jogo $e$ as últimas como os jogadores. Posteriormente, ele afirma que as instituições determinam as organizações e, ao mesmo tempo, estas afetam a evolução das instituições. Em outras palavras, quando ocorrem alterações, é gerada, temporariamente, uma situação de

14 Contudo, nesse processo, existe uma hierarquia nas regras, que vai da Constituição Federal até os contratos individuais, definindo as limitações das regras gerais, bem como as especificidades particulares.

${ }^{15}$ É preciso entender que é mais difícil descrever as regras informais que balizam o comportamento do que as regras formais. Diz-se que as instituições são formais, no caso das leis, ou que são informais, no caso de convenções e códigos de ética. Ambas podem ser criadas ou simplesmente evoluir no tempo. desequilíbrio, que leva os agentes a repensar novas organizações e instituições que estejam adaptadas à situação presente. As organizações políticas ou econômicas competem para transformar as instituições da maneira que mais atenda a seus interesses. Isso quer dizer que as organizações buscam manter o status quo que Ihes interessa ou o modificam, quando o sistema de regras não Ihes permite resolver seus conflitos ou realizar seus objetivos.

É possível remeter esse entendimento a nossa área de estudo $\mathrm{e}$ apontar que não apenas no submédio São Francisco, mas também na região Nordeste do país, as mudanças institucionais específicas e a existência de organizações como IOCS, IFOCS, DNOCS, Chesf, Banco do Nordeste, Sudene e Codevasf constituíram essencialmente os agentes que determinaram a organização do território.

\section{A perspectiva institucional na geografia econômica}

A incorporação da perspectiva institucional na geografia econômica é relativamente recente, e talvez por isso tal discussão encontre-se na periferia dessa ciência.

Todavia, Martin (2000, p.79) aponta que, a partir da década de 1990, houve o reconhecimento de que a evolução da paisagem econômica não pode ser compreendida sem atenção especial às diversas instituições das quais ela depende. Ainda, segundo o autor, a perspectiva institucional na geografia sofreu forte influência dos trabalhos de North e Williamson, principalmente, no que diz respeito ao papel central dos fatores institucionais em todos os níveis de apreensão da atividade econômica. 
Para este estudo, interessa colocar em evidência a distinção dos conceitos de ambiente institucional e arranjo institucional, à medida que eles, ao ser incorporado pela geografia econômica, permitem passar de uma representação do território como simples base de recursos naturais para uma representação que inclui questões sobre o papel, impacto e evolução das instituições no processo de desenvolvimento na diferenciação de regiões, como no caso do submédio São Francisco, localizado na região semiárida do Nordeste. Essa perspectiva não significa, contudo, atribuir às instituições papel exclusivo nas condições de desenvolvimento, mas sim compreender os efeitos do regime institucional na configuração de regiões e territórios.

O conceito de ambiente institucional, compreendido como sistema formal e informal de normas e convenções, atua como suporte para o aproveitamento de recursos específicos no território, permitindo evidenciar mecanismos de coordenação horizontal para os diferentes setores de atividade. A noção de arranjo institucional, por sua vez, denota uma forma particular de organização, como as agências reguladoras, as companhias de desenvolvimento regional, os consórcios municipais etc., que apoiam a formação de um território. O interesse por esses conceitos reside no entendimento de como as organizações econômicas surgem, funcionam, evoluem e criam arranjos influenciados pelo ambiente institucional.

Assim, dentre as mudanças propiciadas pelo diálogo entre a geografia econômica e a perspectiva institucional, salienta-se o reconhecimento do papel do território como componente de um processo de construção de recursos específicos, que implica interações entre agentes econômicos e seu ambiente institucional.

\section{Conclusão}

Ao longo do último século, os investimentos e políticas públicas na região nordestina voltaram-se, basicamente, para ações que envolvessem o uso dos recursos hídricos. A perspectiva adotada ao longo deste trabalho permite compreender as mudanças institucionais e as ações de organizações: DNOCS, Sudene, Banco do Nordeste, Chesf e Codevasf, como responsáveis por uma estruturação do espaço, num processo de construção que nunca para. Mais do que isso, o entendimento de que as ações dessas organizações estão pautadas por instituições formais abre uma possibilidade de análise e de compreensão da dinâmica de longo prazo e das contradições e dos ajustes necessários a toda mudança de caráter estrutural.

Evidencia-se, ainda, que as modificações institucionais não repercutiram na mesma velocidade e intensidade nas organizações e que as últimas podem apresentar resistências importantes para a implantação de mudanças. 


\section{REFERÊNCIAS BIBLIOGRÁFICAS}

ANEEL. Regulação do setor elétrico brasileiro: panorama e tendências. São Paulo, 1999. 29p.

ANDRADE, M. C. de. A seca: realidade e mito. Recife: Asa Branca, 1983. 81p.

BRASIL. Ministério da Integração Nacional. Novos limites. 2004. Disponível em: <http://www.mi.gov.br>. Acesso em: 03 abr. 2004.

BRASIL. Senado Federal. Comissão Especial para o Desenvolvimento do Vale do São Francisco. Relatório parcial $n^{\circ} .1$. Brasília, 1995. Disponível em: <www.senado.gov.br>. Acesso em: jan. 2003.

BRASIL. Lei n.o 3.692, de 15 de dezembro de 1959. Criação da Sudene. Disponível em: <http://www.planalto.gov.br/ccivil_03/leis/19501969/L3692.htm>. Acesso em: 5 fev. 2012.

BRASIL. Lei n.o 6.662, de 25 de junho de 1979. Lei de Irrigação. Disponível em: <http://www.codevasf.gov.br/principal/legisl acao/leis/lei-no-6-662-de-25-de-junho-de1979/>. Acesso em: 5 fev. 2012.

BRASIL. Decreto n.o 89.496, em 29 de março de 1984. Regulamenta a Lei da Irrigação. Disponível em: <http://www.codevasf.gov.br/ principal/legislacao/decretos/decreto-no-89-496de-29-de-marco-de-1984/>. Acesso em: 5 fev. 2012.

BRASIL. Lei n.o 3.995, de 14 de dezembro de 1961. Primeiro Plano Diretor da Sudene. Disponível em: <http://www2.camara.gov.br/legin/fed/lei/19 60-1969/lei-3995-14-dezembro-1961-376756publicacaooriginal-1-pl. html>. Acesso em: 5 fev. 2012.

BRASIL. Lei n.o 4.239, de 27 de junho de 1963. Aprova o Plano Diretor do Desenvolvimento do Nordeste para os anos de 1963, 1964 e 1965, e dá outras providências. Disponível em: <http://www.planalto.gov.br/ccivil_03/leis/L 4239.htm >. Acesso em: 10 fev. 2003

BRASIL. Lei n.o 9.433, de 8 de janeiro de 1997. Adota um novo arranjo institucional para a gestão dos recursos hídricos. Disponível em: <http://www.planalto.gov.br/ccivil_03/LEIS/I 9433.htm>. Acesso em: 10 fev. 2003.

CANO, Wilson. Reflexões sobre o Brasil e a nova (des)ordem internacional. 4.ed. ampl. Campinas: Unicamp, 1995. 208p.

CHESF. Centro de Memória da Eletricidade no Brasil - 50 anos: 1948-1998. Recife, 1998, $136 \mathrm{p}$.
DOMINGUES, R. A. Aspectos institucionais da gestão dos recursos hídricos: o caso do Submédio São Francisco. 2006. 191p. Tese (Doutorado em Geografia) - Universidade Federal do Rio de Janeiro, Rio de Janeiro. Petrolina: crescimento urbano \& intervenção do Estado. 1989. $233 f$. Dissertação (Mestrado em Geografia) Universidade Federal de Pernambuco, Recife. DUTRAIVE, V. (Coord.). L'Économie Institutionnaliste: les fondateurs. Paris: Economica, 1995. 109p.

GOMES, A. M. Imaginário social da seca, suas implicações para mudança social. Recife: FUNDAJ, 1995. 226p. (Estudos e pesquisa, 99).

GUIVANT, J. S. A. A agricultura sustentável na perspectiva das Ciências Sociais. In: VIOLA, E. et al. Meio ambiente, desenvolvimento e cidadania: desafio para as Ciências Sociais. 2.ed. São Paulo: Cortês, 1998. p.99-133.

LAKATOS, E. M. e MARCONI, M. A. Metodologia científica. 3.ed. São Paulo: Atlas, 2000. p.83-98.

LEITE, A. D. A produção de energia do Brasil. Rio de Janeiro: Nova Fronteira, 1997. 528p.

MARTIN, R. Institutional approaches in economic geography. In: $A$ companion to economic geography. London: BlackWell Publishers, 2000. p.77-94.

MARTIN, R. Teoria econômica e geografia humana. In: Geografia humana: sociedade espaço e ciência social. Rio de Janeiro: Jorge Zahar, 1996. p.31-64.

MARTIN, R.; SUNLEY, P. Convergência lenta: a nova teoria do crescimento endógeno e o desenvolvimento regional. Cadernos do IPPUR, Rio de Janeiro, ano 14, n.1, p.15-48, jan./jul., 2000.

MARTÍNEZ COLL, J. C.. Instituciones económicas en la economía de mercado: virtudes e inconvenientes. 2001. Disponível em: <www.eumed.net/cursecon>. Acesso em: 03 mai. 2004.

MINTER/SUDENE. Relatórios Anuais de 1979, 1980, 1981.

MINTER. Uma política de desenvolvimento para o Nordeste. Recife: Sudene, 1985. 83p.

MINTER. Uma política de desenvolvimento econômico para o Nordeste. 2.ed. Recife: Sudene, 1967. 92p.

NORTH, D. C. Desempeño económico en el transcurso de los años. Conferencia de North 
en Estocolmo, Suecia, el 09 diciembre del 1993, al recibir el Premio Nobel de Ciencias Económicas, 1993. 26p. Disponível em: <www.eumed.net>. Acesso em: 03 mai. 2004.

NORTON, R. D. The geography of the new economy: the new economy, three conceptions. Virginia, West Virginia University, 2000. Regional Research Institute. Disponível em: $<$ http://rri.wvu.edu/web_book>. Acesso em: 04 jan. 2005.

NORTH, D. C. Custos de transação, instituições e desempenho econômico. São Paulo: Instituto Liberal, 1992. 38p. (Série ensaios e artigos).

NORTH, D. C. Institutions, institutional change and economic performance. New York: Cambridge University Press, 1990. $152 p$.

NORTH, D. C. Structure and change in economic history. New York: W.W. Norton, 1981.

OLIVEIRA, R. R. A saga dos pioneiros da CHESF. O \& S, Rio de Janeiro, v. 8, n. 20, p. 139-152, jan./abr., 2001.
OLIVEIRA, F. Elegia para uma re(li)gião: Sudene, Nordeste, planejamento e conflito de classes. 3.ed. Rio de Janeiro: Paz e Terra, 1981. 132p.

PASSANEZI, P. M. S. A evolução das instituições segundo Douglas North. 2002. 210f. Dissertação (Mestrado em Economia) Escola de Administração de Empresas de São Paulo, Fundação Getúlio Vargas, São Paulo.

VEBLEN, T. Sobre la naturaleza del capital. Revista de Economía Institucional, Colombia, n. 2, p. 197-216, 2000.

VEBLEN, T. A teoria da classe ociosa: um estudo econômico das instituições. São Paulo: Pioneira, 1965. p.177-197.

WILLIAMSON, O. E. Transactions cost economics and organization theory. Berkeley: University of California, 1993, p.58. 